\title{
VĂN HÓA DOANH NGHIỆP TẠI VIẸTT NAM - DANKO GROUP
}

\author{
DANKO Group
}

February 3, 2019

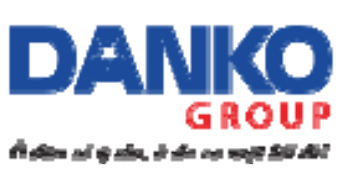

https://dankogroup.com.vn/van-hoa-doanh-nghiep-tai-viet-nam-chong-chenhgiua-cai-cu-va-cai-moi.html 


\section{VĂN HÓA DOANH NGHIỆP TẠI VIẸTT NAM - CHÔNG CHÊNH GIŨAA CÁI CŨ VÀ CÁI MớI}

Có thể nói, văn hóa doanh nghiệp (VHDN) là phần "hồn" của doanh nghiệp. Những năm gần đây, Cùng với sự phát triển của nền kinh tế thị trường định hướng xã hội chủ nghĩa và sự chuyển đổi cơ chế kinh doanh tại Việt Nam, bất kỳ một doanh nghiệp nào nếu thiếu đi yếu tố văn hóa, tri thức thì đều khó đứng vững được.

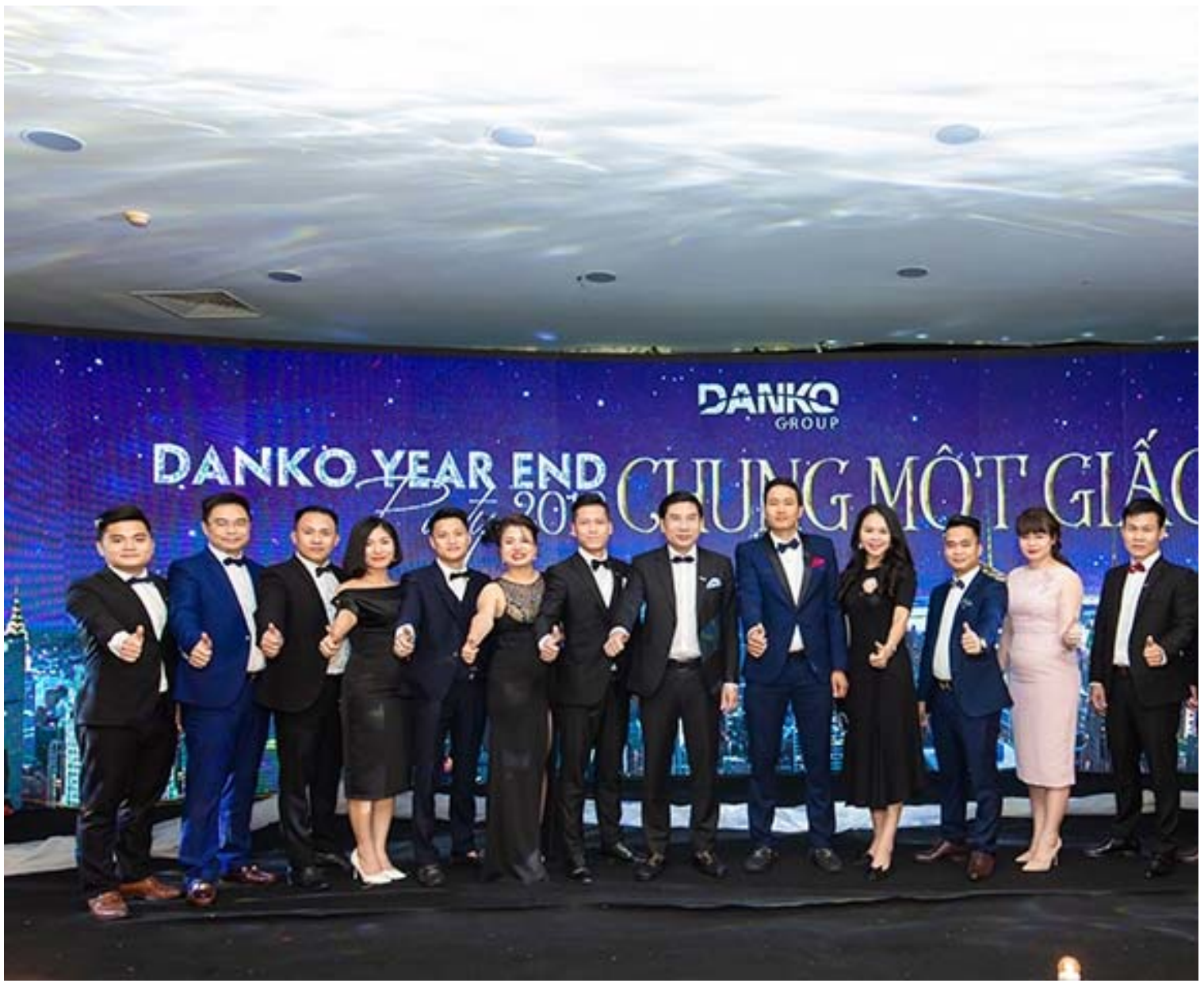

\section{Văn hóa doanh nghiệp - phần "hồn" của doanh nghiệp}

Văn hóa doanh nghiệp không đơn thuần là văn hoá giao tiếp hay văn hoá kinh doanh như ta thường nghĩ. Văn hoá doanh nghiệp là toàn bộ các giá trị văn hoá được gây dựng nên trong suốt quá trình tồn tại và phát triển của một doanh nghiệp, trở thành các giá trị, các quan niệm và tập quán, truyền thống ăn sâu vào hoạt động của doanh nghiệp ấy và chi phối tình cảm, lối suy nghĩ và hành vi của mọi thành viên trong doanh nghiệp để theo đuổi và thực hiện các mục đích của doanh nghiệp. 
Trong cuốn sách Văn minh làm giàu và nguồn gốc của cải của TS. Vương Quân Hoàng, chúng ta đã được đề cập tới khái niệm giá trị. Giải thích một cách đơn giản, giá trị là một cái gì đó mà người ta cảm thấy quan trọng, có ích. Cụm từ "Quan trọng” và "Có ích lợi” là rất đáng lưu tâm trong việc xây dựng văn hóa doanh nghiệp. Bởi lẽ, cốt lõi của văn hóa doanh nghiệp là tinh thần doanh nghiệp và quan điểm giá trị của doanh nghiệp nên nêu lãnh đạo công ty không truyền đạt được những ích lợi mà văn hóa doanh nghiệp đem lại thì doanh nghiệp khó xây dựng văn hóa doanh nghiệp. Tại Việt Nam hiện nay,rất nhiều lãnh đạo đã không nêu rõ được cặn kẽ hệ thống các giá trị văn hóa của doanh nghiệp có ích lợi gì với nội bộ tổ chức nên văn hóa đôi khi biến tướng thành hình thức phong trào.

\section{Văn hóa doanh nghiệp tại Việt Nam - Chông chênh giữa cái mới và cái cũ}

Thời gian gần đây, nhiều doanh nghiệp Việt Nam đã và đang rất quan tâm đến việc xây dựng văn hoá doanh nghiệp, nhiều doanh nghiệp đã có những hướng đi đúng đắn để xây dựng VHDN của mình. Tuy nhiên, doanh nghiệp Việt Nam hiện do vẫn chịu nhiều áp lực về cạnh tranh, doanh thu và lợi nhuận nên việc xây dựng văn hoá doanh nghiệp theo đúng chuẩn mực và mang lại giá trị khác biệt là rất khó. Trong thời kỳ công nghiệp hóa, hiện đại hóa đất nước như hiện nay, tại các doanh nghiệp, đặc biệt là những doanh nghiệp có quy mô lớn, với tập hợp những con người khác nhau về trình độ chuyên môn, trình độ văn hóa, mức độ nhận thức, quan hệ xã hội, vùng miền địa lý, tư tưởng văn hóa... đã tạo nên một môi trường làm việc đa dạng và phức tạp.

Chia sẻ với phóng viên, Ông Trịnh Mạnh Hà - Phó Tổng Giám đốc Tập đoàn Danko cho biết: "Với đặc thù của doanh nghiệp bất động sản, Danko Group xác định vai trò của công tác đào tạo nguồn nhân lực và xây dựng văn hóa doanh nghiệp là vô cùng quan trọng. Văn hóa mà Danko hướng tới chính là Văn hóa con người. Chính vì thế, bên cạnh việc chú trọng vào hoạt động kinh doanh, Tập đoàn luôn luôn xây dựng những lộ trình dài hạn về đào tạo nguồn nhân lực. Ngoài ra, Danko cũng không ngại "tiếp thu", không ngại "thay đổi", không ngại"chi”... để mang đến một môi trường làm việc tốt nhất cho $\mathrm{CBNV}$. Tập đoàn thường xuyên tổ chức các hoạt động giao lưu, gắn kết quy mô lớn dành cho toàn thể gần 1200 CBNV như team building, ngày sinh nhật Tập đoàn, giải chạy vì môi trường Danko Run, Lễ vinh danh 6 tháng đầu năm và 6 tháng cuối năm, Hội xuân Danko được tổ chức mỗi năm một lần vào dịp Tết, ngày truyền thống Tập đoàn, ngày hội tuyển dụng... Ngoài ra, tập đoàn còn liên tục tổ chức các cuộc thi đua trong nội bộ như thi đua doanh số, thi ý tưởng và sáng kiến, thi ảnh đẹp, tổ chức giải thưởng "Trái Tim Danko"... Có thể nói, các hoạt động truyền thông nội bộ đã góp phần tích cực trong việc xây dựng văn hóa doanh nghiệp.”. 


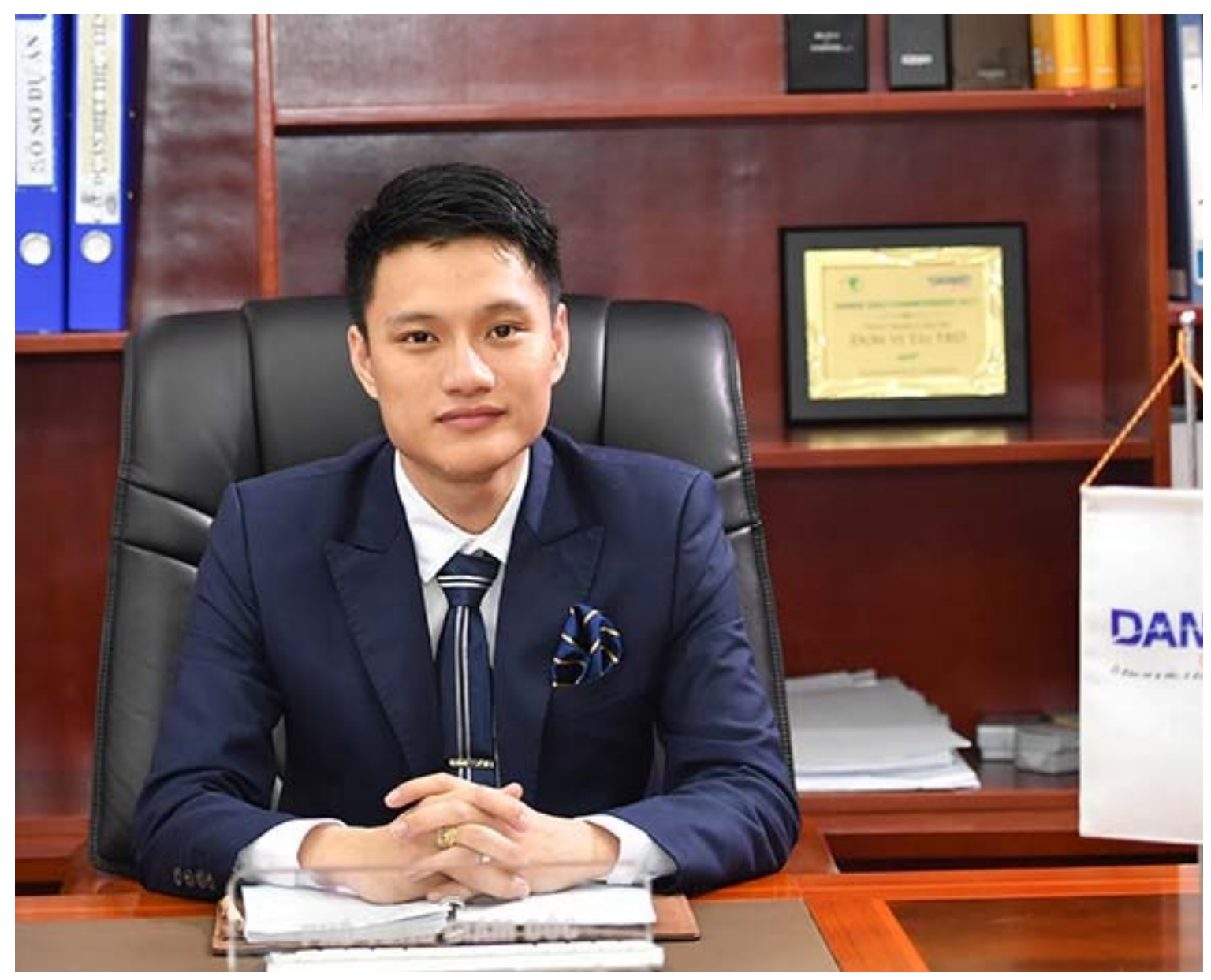

Ông Trịnh Mạnh Hà - Phó Tổng Giám đốc Tập đoàn Danko

"Tuy nhiên, việc khó nhất khi xây dựng VHDN tại Việt Nam là việc làm sao để bản sắc văn hóa dân tộc hòa quyện trong văn hóa doanh nghiệp trong bối cảnh Văn hóa doanh nghiệp tại Việt Nam vẫn đang chông chênh giữa cái mới và cái cũ như hiện nay. Các hoạt động để xây dựng văn hóa phải là những hoạt động thực sự giúp nhân viên hiểu và "ngẩm", chứ không chỉ dừng lại ở hình thức. Do đó, muốn củng cố và phát triển văn hóa doanh nghiệp phải thúc đẩy sự tham gia trực tiếp vào việc xây dựng văn hóa của tất cả các lãnh đạo và quản lý ở mọi cấp độ”. Ông Hà cho biết thêm.

Ngày nay, doanh nghiệp Việt Nam đang đứng trước những cơ hội mới, đặc biệt là sau Hội nghị thượng đỉnh Mỹ - Triều vừa qua, thu hút nhiều khách du lịch, các nhà đầu tư đến Việt Nam, tạo cơ hội lớn đối với ngành du lịch, ngành bất động sản và các ngành nghề kinh doanh khác. Chính vì thế, việc xây dựng văn hóa doanh nghiệp tại Việt Nam đòi hỏi những nhà lãnh đạo phải cóhướng đi đúng đắn và sự lựa chọn sáng suốt để không rơi vào tình trạng quốc tế hóa văn hóa doanh nghiệp. Đó cũng là hướng phát triển lành mạnh, thiết thực để các doanh nghiệp đóng góp ngày càng nhiều hơn vào công cuộc đổi mới, vì mục đích: "dân giàu, nước mạnh, xã hội công bằng, văn minh" mà Đảng ta đã đề ra và được toàn dân ủng hộ.

Theo Bao Congthuong.vn 


\section{Tài liệu tham khảo:}

[1] DANKO Group. (2019). Văn hóa doanh nghiệp tại Việt Nam - DANKO Group. Web.

https://dankogroup.com.vn/van-hoa-doanh-nghiep-tai-viet-nam-chong-chenh-giua-caicu-va-cai-moi.html

[2] Vương Quân Hoàng. (2007). Văn minh làm giàu \& Nguồn gốc của cải. Nxb Chính trị quốc gia, Hà Nội. 